\title{
EXPERIÊNCIA JURÍDICA BRASILEIRA: RACIONALISMO, REALISMO E A FUNÇÃO CRIADORA DO JUIZ
}

\author{
BRAZILIAN LEGAL EXPERIENCE: RATIONALISM , REALISM AND \\ THE CREATOR FUNCTION OF JUDGE
}

\author{
${ }^{1}$ Fábio Luiz Angella \\ ${ }^{2}$ Cesar Augusto Carra
}

\begin{abstract}
RESUMO
Tema bastante atual é o grau e os limites atribuídos ao juiz no processo de construção do Direito. Pautando-se, a premissa central, na suposta superação do caráter dogmático do direito, que eleva a neutralidade do juiz como um de seus característicos, e questionado o método positivista, começaram a despontar correntes modernas, antidogmáticas, e que renegavam o positivismo extremado defendido pela escola da exegese. Classificados como escolas modernas, tais sistemas são representados pelas escolas da livre indagação, do direito livre e histórico-evolutiva. Assimiladas, algumas delas, pela experiência jurídica nacional, este artigo abordará, de maneira superficial, o embate travado entre a dogmática e a zetética jurídica para, apresentando a questão central: equivalência do direito à lei, tecer considerações acerca das principais doutrinas sobre o tema. Após, fará alguns comentários sobre as tendências racionalistas e realistas para, ao fim, criticando a doutrina de Kantorowicz, que parece grassar certa aceitação no cenário jurídico nacional, concluir que o juiz não pode se emancipar, por completo, da lei.
\end{abstract}

Palavras-chave: Interpretação, Escolas, Racionalismo, Realismo, Escola do direito livre

\begin{abstract}
:
Very current theme is the extent and the limits assigned to the judge in the Law building process. And are based, the central premise, the alleged overcoming the dogmatic character of law, which raises the neutrality of the judge as one of its characteristics, and questioned the positivist method, began to emerge modern currents, antidogmáticas, and forswore the extreme positivism defended the school of exegesis. Classified as modern schools, such systems are represented by schools of free inquiry, free and historical and evolutionary law. Assimilated, some of them by the national legal experience, this article will address, in a very superficial way, the clash caught between the dogmatic and legal zetética for presenting the central issue: equivalence of the right to law, to present the main doctrines on the subject. Will make some considerations about the rationalist and realist tendencies, after criticizing the doctrine of Kantorowicz, which seems unabated certain acceptance in the national legal scenario, conclude that the judge can not be emancipated, completely, the law.
\end{abstract}

Keywords: Interpretation, Schools, Rationalism, Realism, The free law school

\footnotetext{
1 Mestre em Sistema Constitucional de Garantia de Direitos pela Instituição Toledo de Ensino. Instituição Toledo de Ensino - ITE, São Paulo. Brasil - E-mail: fabio@angella.adv.br

2 Mestrando em Direito Constitucional pela Instituição Toledo de Ensino. Instituição Toledo de Ensino - ITE, São Paulo- Brasil - E-mail: cescarra@live.com
} 


\section{INTRODUÇÃO}

Quando analisamos o atual estágio da ciência do direito, verificamos que grande parte da doutrina sinaliza que um dos maiores embates a ser sanados no século XXI é a compatibilização do constitucionalismo, com o processualismo e o internacionalismo.

Não olvidando que aquela constatação possa ser verdadeira, para efeitos práticos deste artigo, ocuparemo-nos de uma outra questão, de longa data já debatida, que é justamente as nuances acerca dos atuais rumos da interpretação legal, e suas implicações quanto ao grau de liberdade do juiz no processo de formulação do Direito estatal.

Desde já salientamos que com este arrazoado não pretenderemos esgotar o enfrentamento do tema, nem ao menos concluir nada nesse momento inicial.

Entalhando o tema como um prelúdio de porvindoura obra - cujo título inclusive temos, "A Lei e o Direito", pretenderemos tecer breves considerações acerca das principais correntes que se propuseram ao estudo da situação em tela, e seus reflexos na legislação pátria.

Partindo do caráter dogmático do direito, sinalizaremos que com o passar dos tempos, e a superação da visão hermética oriunda da codificação importada do direito romano, a teoria normativa, fundada no dokéin, foi perdendo seu prestígio, sendo aos poucos substituída pelo espírito questionador (zétein), que inspirou a chamada teoria interpretativa do direito.

Questionando se com isso o direito teria transmudado de uma ciência dogmática para uma ciência zetética, demonstraremos que não distante os frequentes movimentos em prol da consagração do direito alternativo, mesmo após o abandono da escola exegética, o juiz não pode ser considerado um ser absolutamente livre para criar e ditar o direito aplicável in concreto, isso porque, perfilhando-nos à escola de Salleiles, inclusive positivada na experiência jurídica brasileira, o julgador deve atuar num regime de colaboração; ou seja, não deve se apegar exclusivamente a letra fria da lei. Todavia, não pode agir deliberadamente proeter ou contra legem.

Assim, nesse movimento simbiótico, o juiz não poderá substituir as intenções plasmadas (valores), e que inspiraram a edição da lei por seus critérios pessoais de justiça, que corresponderia a decidir por equidade. Num trabalho muito mais importante, o juiz deve desvendar a tríade contida no mandamento legal, compatibilizando-o e aperfeiçoando-o, mas 
nunca desprezando-o, isso porque, desbordando um pouco da teoria egológica de Carlos Cossio, compreendemos que à luz da teoria tridimensional, o direito está compreendido na lei,pois, esta, a contar da concepção do legislador como um ser concreto, racional, e não como um ente abstrato, contém em boa medida um valor, deriva de um fato, contemplando, dessarte, o trinômio fato, valor e norma.

Dessarte, cabe ao juiz desvendar, e não criar tal tríade, em detrimento da atividade desenvolvida pelo legislador.

\section{DOGMÁTICA E ZETÉTICA JURÍDICA}

Tema bastante interessante é a distinção entre dogmática e zetética jurídica.

Consultando as principais obras dedicadas ao estudo da ciência do direito podemos verificar que ecoa em parcela significativa do cenário jurídico nacional a concepção de que o direito, em seu viés moderno, trata-se de uma ciência eminentemente dogmática.

Derivando, o vocábulo dogmática, da palavra primitiva grega dokéin, que significa doutrinar, o direito, assim estabelecido, funda-se na ideia de princípios inquestionáveis, o que é denominado por Luhmann como princípio da proibição da negação.

Constando, aquela denominação, de seus apontamentos sobre sistema jurídico e dogmática, Luhmann acredita que o sistema jurídico-dogmático atua como condição para reduzir as incertezas sociais e do direito, trazendo, assim, segurança jurídica.

Preocupando-se muito mais com respostas do que com perguntas, ainda que não detenha um espírito questionador, pois tudo aceita por fé, a dogmática é posta à prova quando se indaga a forma como se revela e o modo como exsurge o Direito, existindo, para tanto, e basicamente, duas vertentes doutrinárias que se propõem a resolver a inquietação.

Denominada, a primeira, como teoria normativa do direito - que tem como fundamento primacial o dokéin - essa corrente se vaza no argumento de que o que interessa para o direito é o aspecto positivista, isso porque, internalizando o que já era defendido por Napoleão, em seu codex, não tendo participação no processo de criação do Direito estatal, o juiz restringiria-se a condição de mero bouche de la loi, inexistindo outras fontes de inspiração.

Concebendo, duma maneira talvez extremada, que o direito somente poderia ser encontrado na lei, a teoria normativista era contraposta pela teoria interpretativa do direito, que, resumidamente, estribada no zétein, ou seja, no espírito questionador, assentava que o 
juiz estava apto a interpretar a lei, indagando sobre sua exatidão e recorrendo, no caso de omissão ou dúvida, a outros elementos de convicção que não a lei.

Defluindo, desse embate, a pergunta, e o nó górdio da discussão, de ser, ou não, o Direito equiparado à lei, tal inquietação passou a ocupar parcela considerável do cenário jurídico mundial e nacional.

Causando uma verdadeira revolução copernicana, a pergunta, sob uma ótica filosófica - filosofia do direito - ataca o próprio dogma de estruturação, pois, sendo símbolo da ordem estatal, a lei, como produto da vontade geral, era tida como uma figura inquebrantável, dela decorrendo todo o direito.

Infirmando o próprio caráter dogmático do direito, a pergunta poderia implicar na transformação da ciência do direito de dogmática para zetética, pois, até então, seria a lei o único instrumento de regulação do direito.

Com o enfraquecimento da lei, e a revelação de outros fatores que deveriam ser levados em conta pelo juiz por ocasião da prolação de um também ato estatal - sentença - perdeu-se, um pouco, a referência central, não se sabendo distinguir, por ora, e com exatidão, se a lei rege o direito ou se o direito rege a lei.

Tratando-se, aquela pergunta, de questionamento ainda não univocamente solvido, o presente capítulo serve para demonstrar o estopim da crise interpretativa do texto legal.

Desse modo, e sem antecipar conclusões, fixado o âmbito de estudo desta dissertação, podemos seguir com o enfrentamento de outro ponto de discussão, que é justamente a liberdade do juiz, por via da interpretação, de participar do processo de criação do direito.

\section{INTERPRETAÇÃO E CONSTRUÇÃO}

Da questão colocada no capítulo anterior, se o Direito deve, ou não, ser equiparado à lei, emergem as teorias sobre a interpretação.

Vocacionada a fixar um sentido objetivo a um texto jurídico a interpretação, nas precisas lições de Carlos Maximiliano consiste na atividade de:

explicar, dar o significado de vocábulo ou gesto; reproduzir por outras palavras um pensamento exteriorizado; mostrar o sentido verdadeiro de uma expressão; extrair, de frase, sentença ou norma, tudo o que na mesma contém $(2011$, p. 7$)$. 
Resultando na afirmação de que no processo de aplicação o juiz não pode agir como um mero autômato na execução da lei, devendo atuar de maneira intelectiva, a interpretação, por mais que posta ao descobrimento do real significado das expressões, não pode ser totalmente livre, como propugnou Hermann Kantorowicz, nem completamente amarrada, como defendido pela escola exegética.

Necessitando de comedimento, a interpretação deve quedar numa situação intermediária.

Efetuando uma retrospectiva histórica, verificamos que após o enfraquecimento da escola da exegese, que pontificava que o intérprete deveria militar como descobridor da vontade, do intento do legislador, sendo a lei a única fonte do direito estatal, muitas outras escolas surgiram empós.

Classificadas como escolas modernas, pois se contrapunham à tendência tradicional - exegese -, essas escolas poderiam ser subdivididas basicamente em três: a escola da livre indagação; a escola do direito livre; e, a escola da evolução histórica de Salleiles.

Tendo, a primeira, como principais corifeus François Gény e Ehrlich, a escola da livre indagação defendia que no processo de aplicação, o juiz não poderia ficar unicamente adstrito à lei, pois, ainda que fosse esta considerada a mais importante fonte do Direito estatal, não seria a única, podendo o juiz se louvar na doutrina, na jurisprudência ou nos costumes.

Concedendo certa parcela de liberdade ao julgador, alforriando-o dos grilhões da lei, a escola da livre indagação, conquanto de um viés mais realista, deu o matiz para o desenvolvimento de uma corrente bem mais extremada.

Reconhecida como escola do direito livre, bem representada na cátedra de Kantorowicz, esta escola propugnava que o juiz deveria exercer o controle da justiça da lei, pois seria corolário da sua aplicação a existência de um direito justo.

Com isso o juiz poderia censurar a lei, realizando as necessárias correções, inclusive mediante a substituição de seus termos por suas concepções pessoais de justiça.

Instituindo uma verdadeira ditadura judicial, porque o julgador se arrogava na condição de legítimo representante dos anseios sociais, responsável por sua identificação, o juiz se transformava num verdadeiro sociólogo do direito.

Tendenciadas a uma formatação bastante realista, as escolas da livre indagação e do direito livre demonstraram o caráter arcaico, mas sempre atual, do presente tema elegido para a discussão. 
Servindo, nesse momento, apenas para comprovar os embates travados sobre o tema, como pode ser dessumido da leitura dos parágrafos anteriores, remanesce fazermos considerações acerca da terceira escola moderna sobre intepretação.

Fundada por Raymond Salleiles, a escola histórica estriba-se na necessidade de o juiz atuar como um atualizador da lei.

Embora devesse atualizá-la as novas realidades sociais - o que denota o caráter dinâmico da interpretação - a escola evolutiva, fundindo noções apropriadas da escola exegética com ideias atuais, assumindo uma postura conciliadora, afirmava que o juiz, apesar de poder decidir de certo modo por equidade, deveria desvendar o intento, a vontade do legislador, procedendo, assim, uma intepretação evolutiva, a fim de detectar os motivos que impeliram a edição da lei.

Compatibilizando a mens legislatoris com os fins sociais a que a lei se destina e às exigências do bem comum, a escola histórica se aparentou como um modelo ideal, evitandose arbítrios de ambos os lados.

E de tão promissora, da leitura atenta do art. $5^{\circ}$ da vigente Lei de Introdução às Normas de Direito Brasileiro, defrontamos que foi aquela a escola elegida por nossa legislação.

Fornecendo as balizas para a atividade interpretativa, o disposto no art. $5^{\circ}$ da LINDB, incorporando a escola histórica, foi aos poucos sendo deixado de lado pela atuação de nossa jurisprudência.

Desconsiderando o processo de construção de nossa experiência jurídica, e outorgando amplos poderes à figura do julgador - o que beiraria uma nociva concentração - a jurisprudência e a doutrina, dando novo formato a experiência jurídica nacional, no afã de implementar as tendências realistas, importadas do exterior, renegando a asserção lançada pelos antigos sofistas atenienses, no sentido de que o legislador criava o Direito, substituiu, de maneira bastante abrupta, a crença na onipotência daquele pela divinização do julgador.

Dessa descrença, e da multiplicidade de escolas que se destinaram ao estudo do tema, emergiu uma grande bifurcação, qual seja, o formalismo e o realismo no processo de interpretação da lei.

Bastante exploradas, aquelas tendências, pela obra do jurista Luiz Alberto Warat, o renomado autor, no tomo I de sua obra Introdução Geral ao Direito, lecionando acerca da interpretação da lei, propondo alguns pontos para uma reformulação, assenta que: 
Entre os diversos temas tratados pelas duas correntes [formalistas e realistas] salienta-se a discussão sobre o caráter científico ou retórico da atividade doutrinária, a função da norma na sociedade, o caráter criativo ou meramente declaratório da função judicial, as fontes do direito, os métodos de interpretação da lei e o estatuto e propriedades linguísticas das normas gerais (1994, p. 51-52).

Demarcando o âmbito de atuação, Warat, numa visão propedêutica, sinaliza que no "ensino jurídico institucionalizado e as chamadas ciências dogmáticas do direito têm acolhido sempre em suas formulações as teses do modelo racionalista” (1994, p. 52).

Afirmando que a concepção formalista é a que prepondera no sistema jurídico continental, de base romanística - como o é o Brasil - Warat assume que na tendência formalista, ou racionalista, o intérprete parte de um comportamento dedutivo, pois, pressupondo uma ordem jurídica total, racional, acredita "que todas as hipóteses e conflitos particulares podem ser solucionados com fundamento exclusivo no ordenamento legal" (1994, p. 52).

Aproximando-se muito do que defendia Carlos Cossio em sua teoria egológica, a tendência formalista, ou racionalista, pautando-se num legislador racional - que inclusive é símbolo no direito constitucional, bastando ver o princípio da harmonia ou da concordância prática - busca concretizar o valor da segurança jurídica, o que faz mediante a asseguração do "caráter neutro da atividade judicial, a pretensão de uma ciência do direito descomprometido dos atos decisórios e do jogo social” (WARAT, 1994, p. 54).

Fundando um juiz neutro e imparcial, não empolgado em assumir uma posição bolivariana, sagrando-se "herói nacional", a tendência racional, nas lições de Carlos Maximiliano, "tem sempre e por toda parte soçobrado ante a fecundidade persistente da prática judicial"' (2011, p. 39).

Contraposto pela tendência realista, que troca a onipotência do legislador pela figura do Juiz-Deus, o pensamento formalista foi obrigado a dividir espaço com novas proposições.

Retomando a obra de Warat temos que após a desmistificação, no realismo, "o juiz é divinizado como o legislador no formalismo. Contudo nenhum dos dois é protagonista principal da história. São personagens legendários com que nos identificamos e iludimos” (1994, p. 57).

Não passando de uma permutação, o realismo percorre basicamente os mesmos caminhos que o formalismo, só que em sua opinião quem detém as rédeas da situação é o juiz. 
Isso se intensifica quando o realismo afirma ser a lei somente "um álibi, que permite encobrir, tecnicamente, os juízos subjetivos de valor dou juiz. Dito de outra forma, a lei outorgaria uma estrutura racional aos componentes irracionais que determinam a decisão do juiz" (WARAT, 1994, p. 58).

Subtraindo todo resquício de segurança jurídica que poderia existir, a tendência realista, enfraquecida pela pluralidade e pela heterogeneidade de juízes, torna-se caquética, ao ponto de, se contradizendo, buscar outros meios de estabilização, que não a lei, como vimos acontecendo com as chamadas súmulas vinculantes emitidas pelo Supremo Tribunal Federal.

Gerando, esta explanação, uma situação paradoxal, reafirmamos a necessidade de compatibilização, sob pena de geramos o caos.

É por isso que, mesclando os valores entrechocados, e inspirando-nos pelos elementos históricos, propomos que o juiz não deve atuar como investigador da vontade do legislador, como quis a escola exegética, que amparou o formalismo. No entretanto, também não pode substituir o ideário da lei por seus valores pessoais, pois, não sendo sequer representante da nação, não pode se dispor a criar, mas sim a identificar o direito.

Aqui seguimos ao último ponto de nossa dissertação, onde anunciaremos o verdadeiro prelúdio de uma obra que talvez venha a ser escrita um dia.

\section{ESCOLA DO DIREITO LIVRE E A ATUAL EXPERIÊNCIA JURÍDICA BRASILEIRA}

Como salientado alhures, diversamente do propugnado pela escola exegética, o juiz não pode se limitar a atuar como um mero descobridor da vontade do legislador, isso porque, amparando-nos no pontificado por Ronald Dworkin, "a intenção é sempre mais complexa e problemática" (1999, p. 67).

Associando a natureza da intenção com a arte, Dworkin, indagando se a interpretação artística consegue, de fato, descobrir as intenções de um autor, assinala que:

Precisamos reformular nossa primeira pergunta. Se, na arte, uma pessoa quer ver na interpretação a recuperação da intenção de um autor, o que ela deve entender por intenção? Assim reformulada, essa primeira vai dar uma nova forma à segunda. Existe de fato uma distinção 
tão nítida, como supõe a objeção entre descobrir a intenção de um artista e encontrar valor naquilo que ele fez?

Precisamos primeiro lembrar uma observação crucial de Gadamer, de que a interpretação deve pôr em prática uma intenção. $\mathrm{O}$ teatro nos oferece um exemplo elucidativo (1999, p. 67-68).

Concebendo que a interpretação deve por em prática uma intenção, Dworkin frisa que a interpretação:

De modo inevitável, envolve opiniões artísticas do próprio intérprete exatamente como sugere a explicitação construtiva da interpretação criativa, porque tenta encontrar a melhor maneira de expressar, dado o texto em questão, grandes ambições artísticas que Shakespeare nunca formulou ou, talvez, nem mesmo definiu conscientemente, mas que são produzidas por nós ao perguntarmos como a peça que ele escreveu teria sido mais esclarecedora ou convincente para sua época $(1999, \mathrm{p}$. 68).

Podendo, aquela constatação, ser transplantada para o caso presente, já se percebe a dificuldade na definição, no encontro da vontade do legislador, pois, formalista ou racionalista, a atividade do juiz, de menor ou maior modo, sofrerá influência de suas convicções pessoais, não sendo possível, na visão de Dworkin, desapegar-se, o intérprete, de parcela de sua subjetividade.

Tornando tormentosa a questão, reconhecemos que a interpretação segundo a vontade do legislador, de fato, não é uma das melhores técnicas.

No entretanto, existem julgamentos muito extremados que demonstram a concepção hoje reinante, e que chegam a se equiparar com a escola da livre indagação.

De acordo com a experiência jurídica nacional, o juiz não se limita a frase de Portalis, que inaugurava o Código Civil francês.

Indo muito além da mera extensão dos princípios gerais, apoderando-se dos interesses que a lei não satisfez, o juiz, reiteradas vezes, faz prevalecer sua concepção individual, ainda que infringente daquela. 
Encerrando a chamada interpretação contra legem, a atuação do juiz moderno se caracteriza muitas vezes como arbitrária, pois, afora deter a capacidade de julgar, o juiz moderno, muito mais poderoso talvez do que o próprio juiz inglês, tem competência para legislar, existindo um verdadeiro poder normativo do Judiciário.

Desprezando os comandos gerais e abstratos que são plasmados nas leis, e até mesmo infirmando a própria noção de Estado Democrático, a conduta interpretativa do juiz, em franca contradição com a lei, faz renascer a doutrina de François Gény, ou até mesmo as lições de Kantorowicz.

Como pudemos observar no capítulo acima, das escolas modernas, opostas, portanto, ao positivismo defendido pela escola exegética, duas tem importância crucial, justamente pela concessão de amplos poderes à figura do julgador.

Precedida, as escolas modernistas, pelo sistema de François Geny, seguido por Eugen Ehrlich, essa doutrina fez surgir na Europa a voz de Armínio Kantorowicz, a qual é muito bem explorada por Carlos Maximiliano, que em percuciente doutrina, após tecer considerações sobre a tarefa hermenêutica, ou seja, a ciência da interpretação, pontifica que o aludido autor, em laboriosa obra, amplia em demasia a tarefa interpretativa do juiz, conforme segue:

Em vigorosa monografia - A Luta pela Ciência do Direito (Der Kampf um die Rechtswissenschaft), e disfarçado no pseudônimo de Gnaeus Flavius, o docente de Friburgo, em Briscógiva, atira a barra muito longe. Ehrlich e Geny atribuem ao juiz liberdade ampla, relativamente criador, em falta de disposição escrita ou costumeira; portanto, autorizam-no a agir proeter legem. Kantorowicz, embora filiado à mesma escola, induz o magistrado a buscar o ideal jurídico, o Direito justo (richtiges Recht), onde quer que se encontre, dentro ou fora da lei, na ausência desta ou - a despeito da mesma, isto é, a decidir proeter e também contra legem: não se preocupe com os textos; despreza qualquer interpretaçãoo, construção, ficção ou analogia; inspire-se, de preferencia, nos dados sociológicos e siga o determinismo dos fenômenos, atenha-se à observação e à experiência, tome como guias os ditames imediatos do seu sentimento, do seu tato profissional, da sua consciência jurídica. A doutrina revolucionária olha demasiado 
para o foro íntimo, quando deveria, como os moderados e a escola histórico-evolutiva, tomar por ponto de partida a lei, interpretada e compreendida não somente à luz dos preceitos lógicos, mas também de acordo com as ideias, aspirações e interesses legítimos da coletividade (2011, p. 60-61).

Negando pudesse ser a lei considerada como prólogo da aplicação, a escola de Kantorowicz conferia ao juiz amplíssima liberdade, porquanto lhe deferia a capacidade de interpretar não somente proeter, como também contra legem.

Divinizando a figura do julgador, a escola do direito livre defendia o caráter coadjuvante da lei, devendo o juiz ter em conta a justeza, ou não de sua decisão, único guia para a realização do nominado direito justo.

Ora, de difícil definição - bastando ver a divergência doutrinária, e quase infindáveis teorias acerca da real acepção da palavra justiça - a ideia propagada pela Teoria do Direito Justo, a nosso ver, elimina por completo a competência do legislador, pois, apesar dos embates existentes em torno deste, notadamente do desfazimento da crença de que seja o Parlamento o legítimo representante da vontade geral, num sistema codificado, como é o nosso, a lei deve ser a principal fonte de inspiração.

Com isso rebatemos na tecla de que não estamos a sustentar a retomada da escola exegética, que também incorreu em excessos. Adotando uma postura conciliatória, que inclusive é adotada por nosso direito positivo, cremos que a atual missão é encontrarmos um ponto de estabilização, concedendo a capacidade de interpretação ao juiz.

Numa visão bem mais simplista, e tomando por referência as escolas aqui apresentadas, verificamos que nosso ordenamento jurídico, mantendo a tradição, afora se estruturar tendo como primado a lei, perfilhando-se à escola histórico-evolutiva, e até mesmo a teoria de Ehrlich e Geny, deferiu ao juiz a possibilidade de, não somente interpretar a lei sob os auspícios dos fins sociais que a determina, bem como às exigências do bem comum, como também formular a regra para o caso concreto na hipótese de lacuna, de omissão (art. $4^{\circ}$ da LINDB).

Outorgando-lhe capacidade interpretativa secundum e proeter legem, o que nosso ordenamento abomina é a atuação do juiz contra legem, o que subverte toda a nossa experiência jurídica. 
Essa teoria ultra-avançada, que pretende sobrepor o juiz à lei, deve ser analisada cum granus salis, porque, talvez, uma ditadura judiciária não seja menos perigosa do que uma tirania do executivo, ou uma onipotência do legislador, isso porque, toda e qualquer forma de centralização afigura-se como indesejável, ferindo de morte a ordem estatal, como já advertia o barão de Montesquieu.

Como assinala Carlos Maximiliano em laboriosa doutrina:

Substituir a lei (vontade geral) pelo juiz (critério individual), conforme pretende a corte chefiada pelo Professor Kantorowicz, seria retrogradar; a evolução realizou-se no sentido inverso, no de sobrepor a vontade coletiva à de um só. Ora a da maioria acha-se resumida no texto; a de um só homem estaria expressa na sentença proferida segundo os ditames da escola extremada. No campo do Direito Penal, donde, aliás, os corifeus da doutrina pretendem afastar-se, como se fora possível conter a corrente revolucionária deposi de desencadeada;ali o nullum crimen sine lege foi uma conquista; não existia antes; de fato, castigavam os maus, sem invocar a lei, pelo menos até à metade do século XVI, na Europa Central. Também os reis de outrora puniam ou perdoavam segundo lhes parecia justo. Portanto, hoje se planeja elevar o magistrado à altura do soberano absoluto, pelo menos na órbita do Direito Privado (2011, p. 64-65).

Marcando uma involução, a ideia de alforriar o juiz é antidemocrática, pois, além de não ser um bastião do governo representativo, sendo sequer eleito, não pode o magistrado se arrogar na condição de provedor das necessidades sociais, o que o obrigaria a sair de sua zona inercial, transformando-o num super poder.

A cada dia que lemos os boletins de jurisprudência verificamos que é mais frequente o arbítrio do juiz frente a lei.

O juiz, no exercício da judicatura, deve analisar, apreciar, ampliar, integrar o texto legal; mas jamais agir determinadamente contra este, substituindo a lei por sua valoração pessoal.

Persistir na prática, ou seja, na tendência realista de conferir ao juiz a atividade de não apenas participar, como criar, forjar o direito estatal, é dar azo a internalização destes 
alienígenas que hoje ocupam grande parte do cenário jurídico nacional, causando fundadas aflições, v.g, súmula vinculante.

$\mathrm{O}$ vigente direito codificado, bem ilustrado nos dispositivos previstos nos arts. $4^{\circ}$ e $5^{\circ}$ da LINDB dão mostras de que apesar de adepta do civil law, nossa experiência jurídica não considera o juiz como simples boca da lei, conferindo-lhe a capacidade de interpretação.

Para melhor compreensão do tema, seguem os artigos em destaque:

Art. $4^{\circ}$ Quando a lei for omissa, o juiz decidirá o caso de acordo com a analogia, os costumes e os princípios gerais de direito.

Art. $5^{\circ} \mathrm{Na}$ aplicação da lei, o juiz atenderá aos fins sociais a que ela se dirige e às exigências do bem comum.

Ocorre que não distante tal capacidade, a LINDB não libera o juiz das amarras da lei, devendo ser coibido o chamado ativismo judicial, mantendo-se incólume, assim, anos e anos de tradição, sendo esta a visão conciliatória que estamos a propor: siga o Juiz nosso ordenamento conforme lançado, tendo a humildade de reconhecer ser ele, também, subordinado ao império da lei.

A título de arremate cabe uma pequena digressão.

Remontando a origem histórica do primado da lei, verificamos que esta, traduzindo- se na expressão da vontade geral, tinha por fim limitar o absolutismo monárquico oriundo de um regime feudal.

Combatendo o exercício despótico, não seria crível supor que a lei, ou a ordem jurídica, legitimaria eventuais abusos judiciais, isso porque, derivando do antigo regime, a lei, como expressão, signo, da vontade geral - visão rousseauniana, coarctava o exercício do poder estatal, notadamente quando, na letra de Carré Malberg, que interpreta o disposto na Declaração de 1789, tem-se que o ato emanado do legislador, lei:

En los últimos siglos de la antigua monarquia, el rey, sostenido por juristas consagrados a sus pretensiones absolutistas, había conseguido [...] presentarse como propietario personal de la potestade estatal y hasta como constituyendo por sí solo el Estado. La Revolución vino a cortar esta confusión (2001, p. 889). 
Coarctando o poder absoluto antes exercido pela monarquia despótica, o princípio da soberania nacional, consagrado pela Declaração de 1789, "proponía essencialmente retirarle al rey su antiguo poder absoluto, para mitigarlo y restringirlo subordinándolo a la Constitución” (MALBERG: 2001, p. 892).

Retirando o poder absoluto do rei, não era crível supor que a Revolução deferiria a soberania a qualquer outro órgão do Estado, que a exerceria de maneira individual, mas sim de que aquela seria conferida a própria nação, de maneira indivisível.

Ou seja, de acordo com o modelo originário da Revolução Francesa, não pode haver poder supremo, pois suprema é somente a nação.

Disso deflui que qualquer espécie de divinização, seja do Governo, do Parlamento ou do Juiz atentará contra o ideal democrático de um Estado de Direito, isso porque, sendo uma função estatal, está o juiz obrigado a observar a lei.

\section{CONCLUSÃO}

Em conformidade com o que foi acima exposto é possível concluirmos que embora possa vir a ser considerado como uma ciência zetética, o que inclusive é parcialmente defendido por Tércio Sampaio Ferraz Júnior, o direito, em sua tessitura panorâmica atual, necessita ser alvo de profundas reflexões por parte dos jurisconsultos, notadamente no que tange a capacidade construtiva, inovadora, do juiz, mormente quando existentes reflexos negativos que podem advir do ativismo judicial, promanado do realismo jurídico.

Verificamos que de acordo com as principais teorias e escolas da interpretação, parece despontar maior aceitação a escola do Direito Livre, desenvolvida por Kantorowicz, onde predomina a concepção de que o juiz tem a mais ampla liberdade no momento de decidir, redundando num realismo, aliado ao ativismo judicial.

Devendo, aquela asserção, ser encarada com ressalvas, pudemos identificar que de acordo com nosso vigente direito posto, o juiz encontra amarras no corpo da lei, não podendo decidir indistintamente com base na equidade, mormente quando isso é vedado pelo próprio Código de Processo Civil.

Perfilhando-se, nossa experiência jurídica, à escola histórico-evolutiva, o que é comprovado pela leitura do art. $5^{\circ}$ da LINDB, o juiz pode se valer de outras fontes de inspiração, que não a lei, inclusive podendo melhor o conteúdo desta. O que lhe é defeso, e subversivo da 
ordem legal, é vir a, deliberadamente, considerando a lei injusta, substituir os valores nela plasmados por seus ideais pessoais, praticando o que se chama interpretação contra legem.

Podendo, tal situação, vir a causar o caos, pois de acordo com uma visão hobbesiana este seria o resultado se cada um estivesse disposto a interpretar a lei segundo suas próprias concepções, a atividade interpretativa do juiz deve ser comedida, evitando-se a arbitrariedade judicial.

Não refutamos a possibilidade de o juiz, dentro de sua atividade intelectiva, constatando omissão, vir a recorrer aos mecanismos de integração.

O que se veda, ou seja, o que não é possível é que o juiz venha a fazer as vezes do legislador, subministrando em cada caso suas razões pessoais de justiça, sob pena de instalação de uma ditadura judicial, o que, como visto, não é menos nociva do que uma onipotência do legislador ou uma tirania do Executivo.

O que sinalizamos, e numa afirmação que deverá ser melhor aprofundada em momento vindouro, é que o juiz encontra, de fato, limites na lei, devendo sua atuação, quando da resolução da lide, pautar-se pelo direito estatal, cujo vem instrumentalizado na lei, máxima quando normatizando condutas, a lei deriva de um ator constitucionalmente legitimado, evitando-se surpresas por parte do cidadão.

O juiz, em conformidade com este arrazoado, pode atuar como descobridor do intento legal, o que não pode é substituir esse desiderato por seus valores pessoais.

O juiz emancipado do legislador não é próprio de nossa tradição, e pouco prepondera na órbita internacional.

\section{REFERÊNCIAS}

BRASIL. Decreto-Lei n ${ }^{\circ}$ 4.657, de 4 de setembro de 1942. Lei de Introdução às normas do Direito Brasileiro. Diário Oficial [da] República Federativa do Brasil, Rio de Janeiro, RJ, 9 abril 1942. Disponível em: <http://www.planalto.gov.br/ccivil_03/decretolei/Del4657compilado.htm>. Acesso em 13 ago. 2015.

COSSIO, Carlos. Panorama de la Teoría Egológica del Derecho. Buenos Aires: Facultad de Derecho y Ciencias Sociales, 1949.

Radiografía de la Teoría Egológica del Derecho. Buenos Aires: Depalma, 1987. 
DWORKIN, Ronald. O Império do Direito. São Paulo: Martins Fontes, 1999.

FERRAZ JÚNIOR, Tércio Sampaio. Introdução ao Estudo do Direito. 2. ed. São Paulo: Atlas, 1994.

KELSEN, Hans. Teoria Pura do Direito. São Paulo: Martins Fontes, 1999.

LUHMANN, Niklas. Organizacion y Decision. Autopoiesis, Accion y Entendimiento Comunicativo. Barcelona: Anthropos, 2005.

MALBERG, Raymond Carré de. Teoría general del Estado. 2. ed. Panuco: Fondo de Cultura, 2001.

MAXIMILIANO, Carlos. Hermenêutica e Aplicação do Direito. 20. ed. Rio de Janeiro: Forense, 2011.

REALE, Miguel. Lições Preliminares de Direito. 24. ed. São Paulo: Saraiva, 1998.

WARAT, Luiz Alberto. Introdução Geral ao Direito. v. I. Porto Alegre: Sérgio Antonio Fabris Editor, 1994. 